\title{
Adult-onset Still's Disease Secondary to Cytophagic Histiocytic Panniculitis
}

Ai YOSHIDA, Kazunari SUGITA, Nanako YAMADA, Hiroyuki GOTO and Osamu YAMAMOTO

Division of Dermatology, Department of Medicine of Sensory and Motor Organs, Faculty of Medicine, Tottori University, Yonago, Japan. E-mail: ai-yoshida@tottori-u.ac.jp

Accepted Nov 22, 2021; Epub ahead of print Nov 22, 2021

Adult-onset Still's disease is a systemic inflammatory disorder characterized by spiking fever, arthritis, evanescent rash and hyperferritinaemia. Although the pathogenesis of the disease has not been fully determined, activation of macrophages has recently been recognized as a hallmark of adult-onset Still's disease (1). On the other hand, cytophagic histiocytic panniculitis (CHP) is often associated with systemic macrophage activation (2). We report here the first published case of adult-onset Still's disease after CHP.
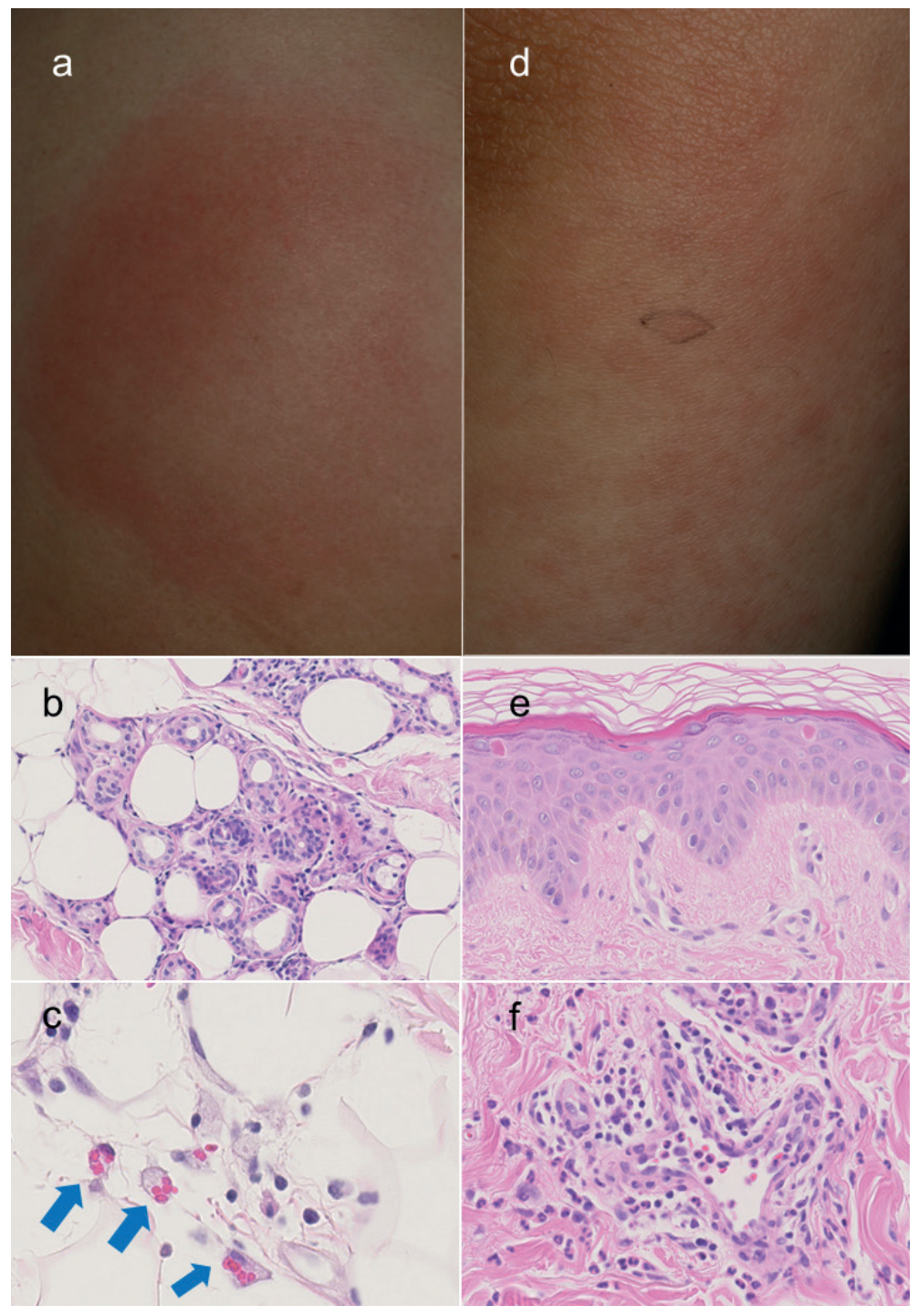

Fig. 1. (a) Clinical findings at the diagnosis of cytophagic histiocytic panniculitis reveal an infiltrative erythema $13 \mathrm{~cm}$ in diameter on her left buttock. (b) A skin biopsy from the buttock shows superficial and deep perivascular and periappendageal lymphocytic infiltration. (H\&E stain; original magnification: $\times 100$ ) (c) Some histiocytes in the subcutis contain erythrocytes (arrow) (H\&E stain; original magnification: $\times 400$ ). (d) At diagnosis of adult-onset Still's disease, the patient had multiple erythematous macules on her extremities with high fever. The figure shows erythemas on the left arm. (e) A biopsy specimen from an erythema on the left forearm demonstrates necrotic keratinocytes in the upper epidermis (H\&E stain; original magnification: $\times 200$ ). (f) A biopsy specimen from an erythema on the right thigh demonstrates superficial perivascular neutrophils in the dermis (H\&E stain; original magnification: $\times 200$ ). 
Four years later, the patient developed multiple erythematous macules on her extremities with high fever (Fig. 1d). The eruptions became worse only when her body temperature increased. In addition, the patient reported pain in her shoulders and the joints of her knees and elbows. The pain and fever $\left(\geq 39^{\circ} \mathrm{C}\right)$ continued for 2 weeks. Blood tests revealed a normal leukocyte count $\left(7.4 \times 10^{9} /\right.$ $\mu \mathrm{l}$; normal range $\left.3.3-8.8 \times 10^{3} / \mu \mathrm{l}\right)$ with increased levels of neutrophils (81\%; normal range $36-70 \%)$, C-reactive protein $(3.57$ $\mathrm{mg} / \mathrm{dl}$; normal range $0-0.19 \mathrm{mg} / \mathrm{dl})$, ferritin $(1,405 \mathrm{ng} / \mathrm{ml}$; normal range $11.0-306.8 \mathrm{ng} / \mathrm{ml})$, and IL-6 $(13.8 \mathrm{pg} / \mathrm{ml}$; normal range 0-4.0 pg/ml). Red blood cell and platelet counts were within normal ranges. Peripheral blood revealed the absence of atypical lymphocytes with normal soluble IL-2 receptor (386.9; normal range 145-519 U/ml) level. Rheumatoid factor quantification, antinuclear antibody, anti-DNA antibody (radioimmunoassay), and anti-Sm antibody, anti-RNP antibody, anti-CCP antibody, anti-ARS antibody and MPO-ANCA were negative. Serum level of C4 (24.0; normal range 17-45 mg/dl) was normal, but serum levels of C3 (169.0; normal range $86-160 \mathrm{mg} / \mathrm{dl}$ ) and CH50 (81.7; normal range $31.6-57.6 \mathrm{U} / \mathrm{ml}$ ) were slightly elevated. Initial infectious work-up, including blood and urine cultures, was negative. In addition, Epstein-Barr virus, human parvovirus B19 and cytomegalovirus infections were excluded by the blood test. Computerized tomography (CT) demonstrated a supraclavicular fossa and mediastinal lymphadenopathy. Furthermore, lymph node biopsy from left subclavicular lymph node revealed no atypical lymphocytes and no monoclonality, based on the histopathological and flow cytometric analysis. The patient had no family history of autoinflammatory disorders. The blood tests and CT findings excluded the possibilities of infections, malignancies and rheumatic diseases. A biopsied specimen from an erythema revealed necrotic keratinocytes in the upper epidermis, focal dermal oedema and perivascular neutrophilic infiltration in the superficial and deep dermis (Fig 1e, f). Based on symptoms, laboratory data and histopathological findings, a diagnosis of adult-onset Still's disease was made, according to Yamaguchi's criteria (3). PSL, steroid pulse therapy, cyclosporine and cyclophosphamide were not effective, but tocilizumab treatment induced remission.

\section{DISCUSSION}

To our knowledge, this is the first published case of adult-onset Still's disease after CHP. CHP is a rare form of panniculitis, histopathologically characterized by infiltration of benign-appearing cytophagic macrophages into the subcutis (2). Some authors recommended using the term "panniculitis-like subcutaneous lymphoma with cytophagocytosis" (4). There was no obvious atypia in the lymphocytes at the time of diagnosis of CHP in the current case. We should, however, consider that our case could be in the smoldering state of panniculitis-like subcutaneous lymphoma, as mentioned by Wick et al. (4). Although the pathogenesis is unknown, CHP has been reported in association with systemic macrophage activation syndrome (5). Intriguingly, adult-onset Still's disease is thought to be associated mainly with activation of macrophages and neutrophils, followed by a cytokine storm, and it is frequently complicated by macrophage activation syndrome (6). Characteristically, IL-6, IL-18, TNF- $\alpha$ and IFN- $\gamma$ are known to be elevated in patients with the active phase of adult-onset Still's disease (7). IL- 6 is produced by macrophages and the increased level of IL-6 suggests that activation of macrophages was involved in the current case. It has been reported that serum levels of IL-6 in patients with active untreated adult-onset Still's disease have been found to be elevated compared with healthy controls (8). Therefore, we believe that the serum level of IL-6 $(13.8 \mathrm{pg} / \mathrm{ml})$ could be associated with the development of the diseases. However, further studies are needed to explore the role of IL-6 in the pathogenesis of the disease.

In conclusion, CHP and adult-onset Still's disease might have a common background, namely activation of macrophages. When clinicians encounter a patient with CHP, the possibility of complications of adult-onset Still's disease should be considered.

The authors have no conflicts of interest to declare.

\section{REFERENCES}

1. Giacomelli R, Ruscitti P, Shoenfeld Y. A comprehensive review on adult onset Still's disease. J Autoimmun 2018; 93: 24-36.

2. Aronson IK, Worobec SM. Cytophagic histiocytic panniculitis and hemophagocytic lymphohistiocytosis: an overview. Dermatol Ther 2010; 23: 389-402.

3. Yamaguchi M, Ohta A, Tsunematsu T, Kasukawa R, Mizuahima $\mathrm{Y}$, Kashiwagi $\mathrm{H}$, et al. Preliminary criteria for classification of adult Still's disease. J Rheumatol 1992; 19: 424-430.

4. Wick MR, Patterson JW. Cytophagic histiocytic panniculitis a critical reappraisal. Arch Dermatol 2000; 136: 922-924.

5. Bader-Meunier B, Fraitag S, Janssen C, Brochard K, Lamant L, Wouters C, et al. Clonal cytophagic histiocytic panniculitis in children may be cured by cyclosporine A. Pediatrics 2013; 132: e545-e549

6. Wang MY, Jia JC, Yang CD, Hu QY. Pathogenesis, disease course, and prognosis of adult-onset Still's disease: an update and review. Chin Med J (Engl) 2019; 132: 2856-2864.

7. Hoshino T, Ohta A, Yang D, Kawamoto M, Kikuchi M, Inoue $Y$, et al. Elevated serum interleukin 6, interferon-gamma, and tumor necrosis factor-alpha levels in patients with adult Still's disease. J Rheumatol 1998; 25: 396-398.

8. Chen D-Y, Lan J-L, Lin F-J, Hsieh T-Y. Proinflammatory cytokine profiles in sera and pathological tissues of patients with active untreated adult onset Still's disease. J Rheumatol 2004; 31 : 2189-2198. 